\title{
Influence of Benzodiazepines on Auditory Perception
}

\author{
N Morand-Villeneuve*,', C MicheyI', MC Gagnieu' ${ }^{2}$ P Lemoine ${ }^{3}$, P Sebert ${ }^{4}$, L Collet' and E Veuillet' \\ 'UMR CNRS 5020, Laboratoire Neurosciences et Systèmes Sensoriels, Lyon, Cedex, France; 'Laboratoire de Pharmacologie, Hôpital Edouard \\ Herriot, Lyon, France; ${ }^{3}$ Unité clinique de Psychiatrie Biologique, Le Vinatier, Bron, France; ${ }^{4}$ Pharmacie du CHS le Vinatier, Bron, France
}

\begin{abstract}
The aim of this study was to test for an influence of benzodiazepine (BZD) on various perceptual and/or cognitive auditory processes. Loudness, auditory selective attention, and the ability of subjects to form perceptual streams out of alternating tone sequences were tested. Nine subjects were tested before, I, 3, 7, and $24 \mathrm{~h}$ after a single-dose oxazepam vs placebo administration in a crossover design. A sample of blood allows us to measure plasma oxazepam concentration. The results revealed a significant reduction in stream segregation expressed as $d^{\prime}$ scores I h after oxazepam intake in the test subjects. No significant change occurred across time in the same subjects when they were administrated a placebo in another session. Furthermore, oxazepam had no substantial and systematic influence either on auditory selective attention or on loudness perception. Altogether, these results suggest that the perceptual organization of sound sequences involves inhibitory neural mechanisms, which can be affected by BZDs. This outcome is consistent with existing models of auditory stream segregation and may be paralleled with earlier findings on the effect of BZDs on perceptual binding in the visual modality Neuropsychopharmacology (2003) 28, 778-786. doi:I 0. I038/sj.npp. I 300072
\end{abstract}

Keywords: benzodiazepines; auditory perception; loudness; auditory selective attention; streaming

\section{INTRODUCTION}

The first benzodiazepine (BZD) was introduced into clinical practice 39 years ago, and since then these tranquilizers have not only largely replaced barbiturates but have become among the most used drugs. The main effects of BZDs are well known; they include a sedative, an anxiolytic, a muscle relaxant, and an anticonvulsivant action. As regards their side effects, besides habituation (Woods et al, 1987), BZDs have been shown to have a detrimental influence on certain cognitive or perceptual abilities, such as memory (Clarke et al, 1970; Brown et al, 1982, 1989; Knopman, 1991; Danion et al, 1992; Sellal et al, 1992) and attention (Johnson et al, 1995; Carter et al, 1998). However, none of these studies have involved the auditory sensory modality. Therefore, in spite of the obvious importance of auditory perception in everyday life, the influence of BZDs on the processing of auditory stimuli remains largely undocumented. The general aim assigned to this study was to test for an influence of BZD on various perceptual and/or cognitive auditory processes. These perceptual alterations can be explained in the light of the known mode of action of BZDs, which act by facilitating the gamma amino-butyric acid

* Correspondence: Dr N Morand-Villeneuve, Laboratoire de Neurosciences, Université de Franche-Comté, I, place Leclerc, 25030 Besancon Cedex, France, Tel: +33 381665 728, Fax: +33 38I 665 754, E-mail: nadege.morand-villeneuve@univ-fcomte.fr

Received 12 February 2002; revised 22 August 2002; accepted 19 September 2002

Online publication: 25 September 2002 at http://www.acnp.org/ citations/Npp092502393
(GABA) (Choi et al, 1977; Macdonald and Barker, 1978), that is, by increasing the affinity of the receptor GABA/A for GABA and by enhancing the ability of GABA to increase the permeability of a chloride ion channel. GABA, the main inhibitory neurotransmitter of the central nervous system (Sivilotti and Nistri, 1991), is also largely present in the auditory system. A number of investigators have shown that neurons, fibers, and terminals containing GABA or its synthesizing enzyme glutamic acid decarboxylase are present in auditory structures at every level from the cochlear nucleus to the thalamus (eg Adams and Mugnaini, 1984; Muganini and Oertel, 1985; Thompson et al, 1985; Wenthold et al, 1986; Peyret et al, 1986; Moore and Moore, 1987; Helfert et al, 1989; Dupont et al, 1990, Vater et al, 1992; Wynne et al, 1995, Fubara et al, 1996), as well as in the auditory cortex (eg Winer, 1986).

The first hypothesis addressed in this study was inspired by the observation that the withdrawal of BZDs after longterm usage can in some cases induce hyperacousis and tinnitus - that is, phantom auditory sensations (Busto et al, 1988; Lader, 1994; Petursson, 1994). The first aim assigned to the present study was to test a modification of auditory sensitivity by measuring the effect of BZD intake on loudness judgments.

The effects of BZDs on two other aspects of auditory perception have also been investigated in the present study, namely selective auditory attention and auditory streaming. Selective attention refers to the capacity to process target stimuli and ignore other, irrelevant and potentially interfering stimuli. Numerous experimental data in the literature suggest that the neurophysiological basis of selective 
attention could lie in the inhibition of neural responses to the irrelevant aspects of the stimulation (Walley and Weiden, 1973; Desimone and Duncan, 1995; Clark, 1996). It has been shown that the unitary responses of neurons in the visual cortex to unattended stimuli were dramatically reduced (Moran and Desimone, 1985). In the auditory modality, measures provided by event-related potentials (ERPs), by magnetoencephalographic recordings (MEG), the use of neuroimaging techniques such as functional magnetic resonance imaging and positron emission tomography have enriched the physiological models of selective attention and the brain structures involved in this process (Giard et al, 2000). The following are examples of attention effect: (1) Functional imaging studies using PET revealed a decreased activity in auditory areas of the cortex that process input from unattended tones (Kawashima et al, 1999; Ghatan et al, 1998). This decreased activity has been interpreted as a 'top-down inhibitory modulation' of a nonattended input (Ghatan et al, 1998). (2) Focused auditory attention in humans could selectively modulate auditory cortex; in this way, tones in the attended ear evoked larger magnetic brain responses than in the unattended ear (Woldorff et al, 1993), suggesting a mechanism of sensory gain control. (3) The $40 \mathrm{~Hz}$ response in the $\gamma$-band $(40 \mathrm{~Hz})$ frequency is larger when subjects paid attention to stimuli (Tiitinen et al, 1993). (4) The mismatch negativity (MMN), the negative brain potential elicited by a deviant stimulus, is also modulated by attention; $M M N$ to unattended-ear deviants are attenuated (Woldorff et al, 1998). To sum up, it appears that selective attention could act both through enhancing the processing of target input as well as by suppression of competing inputs. In the psychoacoustic test, selective attention is reflected in a decrease of correct detection percents for tones of unattended frequencies (Scharf et al, 1987; Scharf, 1989; Dai et al, 1991). If this perceptual phenomenon is effectively underlain by neural inhibitory processes, like lateral inhibition, then it should be altered by substances like BZDs, which act upon GABAergic pathways. Furthermore, it has recently been shown that the functioning of the medial olivocochlear system, an auditory efferent subsystem the surgical section of which has been shown to reduce auditory selective attention (Scharf et al, 1994, 1997), was altered by BZDs (Morand et al, 1998). In order to test the general hypothesis of an influence of BZDs on auditory selective attention, we measured selective auditory attention before and at several moments after BZDs or placebo intake in subjects using a crossover double-blind paradigm.

The third aspect of auditory perception, which was addressed in this study, consists of the analysis of perceptual auditory scenes. Auditory scene analysis refers to the process whereby the auditory system analyzes mixtures of sounds to recover descriptions of individual sounds. Streaming refers to a sequential process of auditory scene analysis, whereby successive tones are grouped, or on the contrary segregated by the auditory system to form one or several perceptual streams upon which attention can later be directed (Bregman, 1990). In real-life situations, this process allows one to follow the sound of a violin while other instruments are playing in the orchestra. In laboratory situations, the phenomenon can be investigated experimen- tally using repeating $\mathrm{ABA}$ sequences of tones, where A and $B$ correspond to tones of different frequencies. It is demonstrated that when the frequency separation between the $\mathrm{A}$ and $\mathrm{B}$ tones is small enough, or the tempo is low enough, the sequence is perceived as a single melodic line (ie one stream). But when the frequency separation becomes large enough, or the tempo is too rapid, the sequences splits into two streams: one composed of the B tones, and the other composed of the A tones and having a quicker tempo (van Noorden, 1975). To date, the mechanisms of streaming remain uncertain. Two main explanations have been offered. According to the first, the formation of auditory streams is governed by preattentive, automatic processes (Bregman and Campbell, 1971; Bregman, 1990). According to the second, the formation of auditory streams is related to selective auditory attention processes (Jones, 1976; Jones et al, 1978). The neurophysiological basis of these processes, whether they be automatic or attentional, remains unknown. A peripheral substrate for automatic stream segregation mechanisms is suggested by Beauvois and Meddis $(1991,1996)$. These authors have shown that several aspects of the perceptual organization of alternating-tone sequences could be successfully accounted for by a model based on reciprocal excitation and inhibition between the outputs of peripheral auditory channels. Schematically, in this model, streaming is construed as a selective attenuation of some elements in a sound sequence, which appear as a background stream, while in the other, unattenuated elements form the foreground stream. Recently, a phenomenological model has been proposed, which also involves a balance between inhibitory and excitatory processes to explain perceptual stream segregation (McCabe and Denham, 1996). Together, these models suggest that a key feature of the processes underlying streaming segregation consists of an interplay between inhibitory and excitatory interactions between neurons responding to different frequencies. Indeed, BZD-enhancing GABAergic neurotransmission could modify auditory stream segregation. As mentioned above, besides the interpretation of streaming as a result of automatic mechanisms, another explanation put forward is in terms of auditory attention. Very recent results in the literature indicate that the build-up of auditory stream segregation over time depends on whether the alternating tone sequence is attended to by the listener or not (Carlyon et al, 2001). Since BZDs have been shown to have a detrimental effect on attention (Carter et al, 1998; Johnson et al, 1995), one may predict an effect of BZD in streaming. Another explanation of streaming is in terms of selective attention. Indeed, if BZDs narrow the attentional frequency range, and if streaming depends on the subject's ability to focus attention on tones occurring at a given frequency, stream segregation should be enhanced by BZDs.

\section{MATERIALS AND METHODS}

\section{Subjects}

The study involved 12 healthy male subjects ranging in age from 20 to 25 years (mean: 21.75; SE: 0.524). However, only the results of the nine subjects who completed all measurements are presented in this manuscript. They were 
selected according to the following auditory criteria: normal auditory thresholds $(<20 \mathrm{~dB}$ loss between 250 and $8000 \mathrm{~Hz}$ by octave) measured by a Madsen DAIII audiometer, normal tympanometric recordings. A questionnaire and a medical examination further enabled the selection of subjects having no history of auditory pathology, no medical treatment, and using no hypnotics or BZD substance. On the day of the testing session, a urine assay for BZD was made to confirm that the last of these conditions was met. Subjects were tested on two occasions at 2-week intervals and received either placebo, or $20 \mathrm{mg}$ of oxazepam orally, under double blind conditions. All subjects were volunteers. The written, informed consent of each subject and the agreement of the local Institutional Ethics Committee were obtained.

\section{Psychoacoustic Tests}

Psychoacoustic tests were made before, $1,3,7$, and $24 \mathrm{~h}$ after placebo or oxazepam intake.

Loudness functions measurements. Loudness functions were measured using a loudness-scaling procedure in which subjects had to rate the loudness of pure tone presented at different pressure levels using the following marks: INAUDIBLE (In), TOO SOFT (TSo), COMFORTABLE BUT SOFT (CSo), COMFORTABLE (C), COMFORTABLE BUT LOUD (CLo), LOUD (Lo), VERY LOUD (VLo), TOO LOUD (TLo). This procedure was described in a previous study. First, the absolute hearing threshold and the maximum bearable level for a tone of $1 \mathrm{kHz}$ were measured. Then, the tones were presented at all levels comprised between absolute-hearing and maximum-bearable levels, in $5 \mathrm{~dB}$ steps. Each level was presented 3 times, in random order. On each presentation the subject was asked to rate the loudness using one of the eight categories indicated above.

Auditory selective attention. Auditory selective attention was measured following the probe-signal method devised by Greenberg and Larkin (1968). For the listener, the task is of detecting a brief tonal signal tone that followed a cue tone, in a continuous noise. Like this, on each trial, the subjects' task was to report whether a brief signal followed a cue tone or not. The signal was present in $80 \%$ of the trials. In $60 \%$ of the trials, it had the same frequency as the cue tone, namely $1 \mathrm{kHz}$; in $20 \%$ of the trials, it was presented at another frequency, chosen randomly, with equal frequency (5\%) among the following frequencies: 735, 934, 1066, and $1266 \mathrm{~Hz}$. In fact, since five blocks of 40 trials were performed by each subject in a given measurement session, correct detection percents for signals presented at a different frequency than the cue frequency were based on 10 presentations each. Correct detection percents for signals at the cue frequency were based on 120 presentations. In order to take into account this unequal number of observations, as well as the false alarms - an estimate of which was obtained by counting the number of trials in which the signal was absent but for which the subject had reported hearing it - the results were analyzed in terms of signal detection theory. Thus, the subject's detection performance at the different frequencies was expressed as the detectability index $d^{\prime}$.
Both the cue and the signal tones had a $50-\mathrm{ms}$ overall duration. The cue tone came $200 \mathrm{~ms}$ after the onset of an 850 -ms burst of broadband noise. The signal came $500 \mathrm{~ms}$ after the offset of the cue tone, that is, $50 \mathrm{~ms}$ before the noise ended. All signals were gated on and off using $20-\mathrm{ms}$ cosine ramps. The noise level was set to $30 \mathrm{~dB}$ above its absolute threshold, that is, at $30 \mathrm{~dB}$ SL. The absolute threshold of the noise was measured beforehand in each subject using a computerized dichotomic-search procedure. The signal level was set to $2 \mathrm{~dB}$ above its masked threshold in noise; the cue tone level was $6 \mathrm{~dB}$ above that of the signal, that is, $8 \mathrm{~dB}$ above the masked threshold of the signal.

The signal masked threshold was measured just after the absolute threshold of the noise, and just before the probesignal test. Its measurement involved a two-interval, two-alternative forced choice (2IFC) procedure. In this procedure, the subject's task was to indicate which of the two successive bursts of noise contained a tone pip. As in the probe-signal test, the tone to be detected came $750 \mathrm{~ms}$ after the onset of the 850-ms background noise. Following a two down, one up adaptive tracking rule, the signal level was reduced by a given amount after two consecutive correct responses, and increased by the same amount after each incorrect response. The step size, of $5 \mathrm{~dB}$ initially, was reduced to $2.5 \mathrm{~dB}$ after the fourth reversal in signal level. The procedure stopped after 12 reversals. The threshold was computed as the arithmetic average of the last eight reversals. This threshold obtained, the probe-signal test began.

Streaming. Stream segregation was measured using a constant-stimuli procedure. Following a paradigm devised by van Noorden (1975), subjects were presented with repeating $A B A$-tone sequences, where ' $A$ ' and ' $B$ ' represent tones of different frequency. Subjects were instructed to indicate whether that they were hearing, at the end of the 8-s sequence, either a single auditory stream with a galloping rhythm or two separate streams. Subjects indicated their response by pressing ' 1 ' or ' 2 ' on a computer keyboard.

Each sequence was formed of three $100-\mathrm{ms}$ tones (A-BA) with no silent gap. The three-tone sequence was separated by a $100-\mathrm{ms}$ interval. Signal A was fixed at $1 \mathrm{kHz}$, whereas signal B discretely varied between 1122 and $2000 \mathrm{~Hz}$ (ie 1122, 1259, 1414, 1587, 1781, and $2000 \mathrm{~Hz}$ ). We fixed the number of trials for each condition at 8 . The signal level was set to $30 \mathrm{~dB}$ above the threshold in quiet. All signals were gated on and off using 20 -ms cosine ramps.

The results of this streaming experiment were analyzed in terms of signal detection theory. The number of 'twostream' responses given by the subject in the case where the frequencies of $\mathrm{A}$ and $\mathrm{B}$ tones were the nearest (ie B-tone at $1122 \mathrm{~Hz}$ ) was used to estimate a 'false-alarm' rate. On the basis of the hit and false-alarm rates, the streaming performance could be expressed as $d^{\prime}$ for the different frequency separations tested. To prevent infinite $d^{\prime}$ values in the case where hit rates were equal to $100 \%$ and to account for the limited number of experimental observations, the number of responses corresponding to hits, misses, and correct rejections were all increased by 0.5 before $d^{\prime}$ scores were computed (Snodgrass and Corwin, 1988; MacMillan and Creelman, 1991). 


\section{Statistical Analysis}

Analyses of variance (ANOVAs) on repeated measures were performed in order to test for differences in streaming data between the placebo and control conditions as well as across sessions and frequency separations. Three-way ANOVAs were performed at first in order to obtain a global picture of the main effects of these factors and of their interactions. Then, two-way ANOVAs were applied on selected subsets of data in order to get further insight into the effects of certain factors in specific conditions. The same approach was used to study the effect of frequency, treatment, and test session on detection performance in the auditory selective attention task and, finally, the effect of signal level, session, and treatment on loudness estimates in the categorical loudness estimation task. In all these analyses, the level of statistical significance was set to $p<0.05$.

\section{RESULTS}

\section{Plasma Concentration of Oxazepam}

Figure 1 shows the mean plasma concentration of oxazepam. The highest plasma concentration was found $3 \mathrm{~h}$ after intake. This result is consistent with data in literature (Knowles et al, 1972). Individual variations in maximum plasma concentration are apparent in the results, with values ranging between 0.195 and $0.521 \mathrm{mgl}^{-1}$ (mean: 0.344; SE: 0.03).

\section{Loudness Functions}

Figure 2 shows the average intensities corresponding to the nine different loudness categories after placebo and

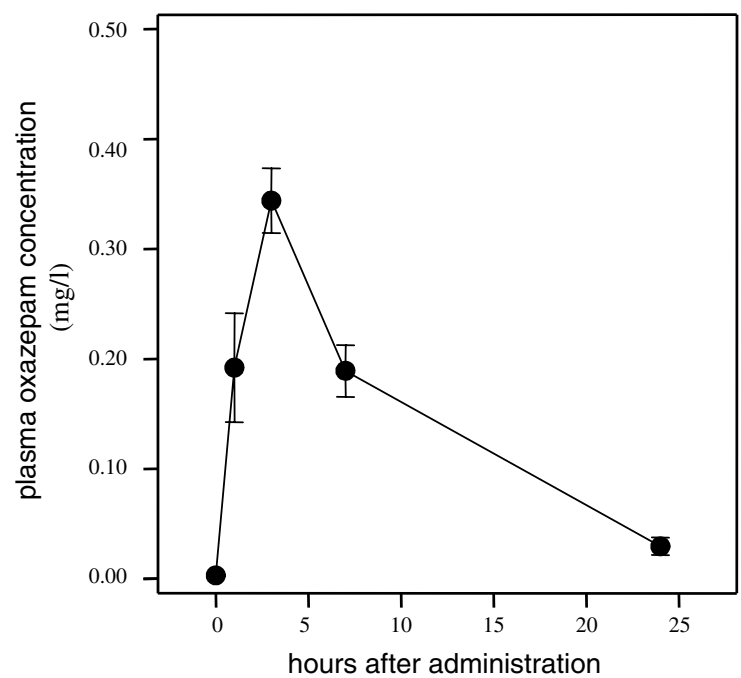

Figure I Plasma concentration as a function of time. The figures on the abscissa indicate hours relative to oxazepam intake. The 0 -h point corresponds to the plasma concentration measured just before the administration. The mean plasmatic concentration of oxazepam is measured in $\mathrm{mg} / \mathrm{l}$ on the ordinate. The errors bars represent the standard errors around the means.

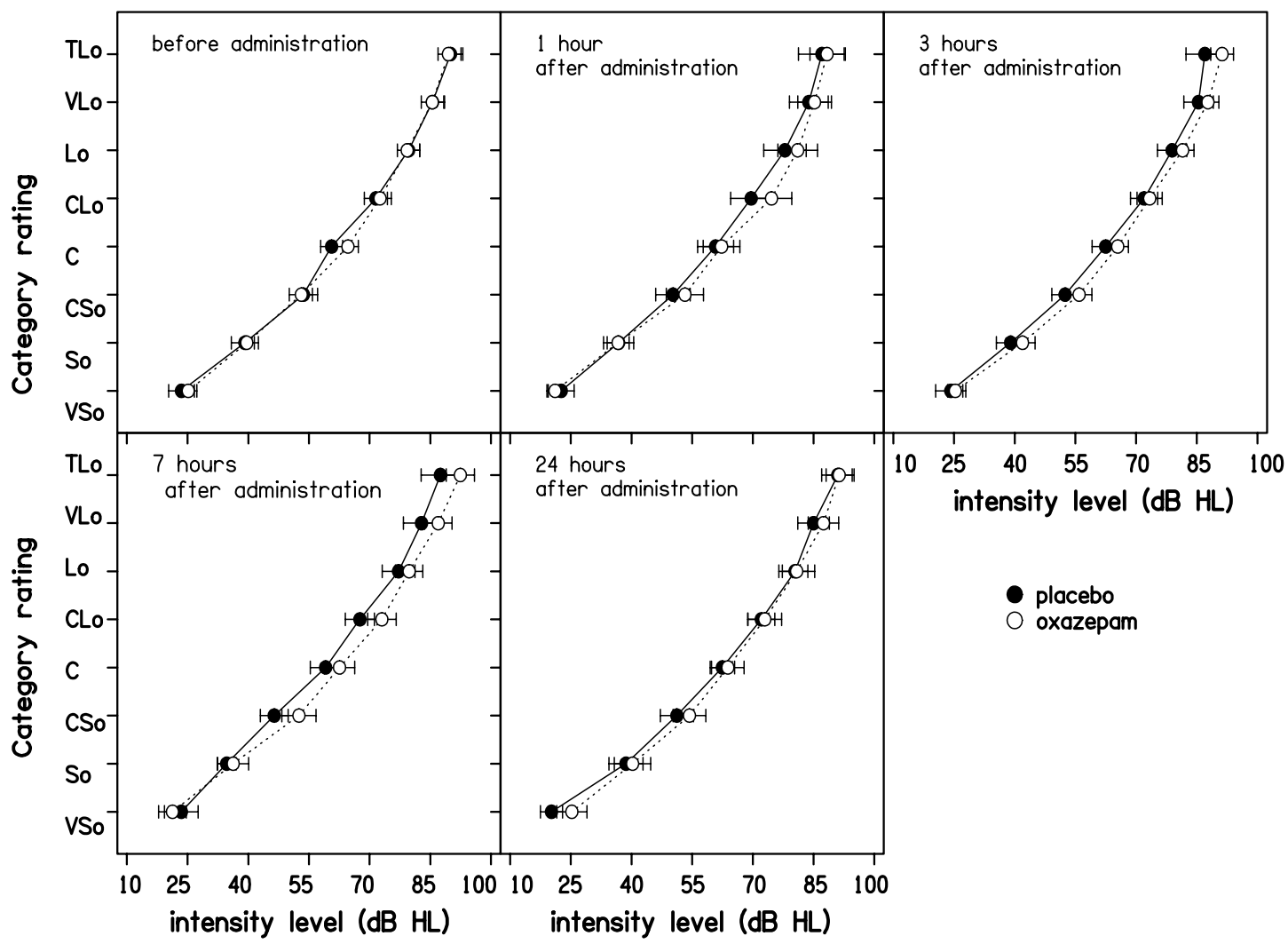

Figure 2 Loudness functions measured under placebo and oxazepam on the different test sessions. The values on the abscissa indicate the mean signal level in $\mathrm{dB} \mathrm{HL}$ corresponding to the different loudness categories represented on the ordinate. The data points correspond to averages across the nine subjects, and the error bars represent the standard errors around the means. The filled circles correspond to data obtained in the placebo condition; the empty circles correspond to data obtained under oxazepam. 
oxazepam intake, for the different sessions, that is, before, 1 , 3,7 , and $24 \mathrm{~h}$ after intake. The data were analyzed firstly using a three-way repeated-measures ANOVA (level $\times$ session $\times$ treatment). The results indicated an effect of level $(\mathrm{F}(5,40)=709.617, p<0.001)$, but neither of treatment $(\mathrm{F}(1,8)=0.086, p=0.777)$ nor of session $(\mathrm{F}(4,32)=0.831, p=0.516)$. Furthermore, no interaction between factors was observed. In order to check whether this lack of significance was because of the few data points under which differences could occur being drawn into the various other data points at which no difference was expected, we then performed ANOVAs for the placebo and oxazepam data alone. The results of a two-way repeatedmeasures ANOVA (level $\times$ session) on the data under placebo showed, not unexpectedly, a highly significant effect of stimulus level $(\mathrm{F}(5,40)=480.817, p<0.001)$, but not of session $(\mathrm{F}(4,32)=0.644, p=0.635)$ on loudness. The same analysis on the data under oxazepam led to the same result $((\mathrm{F}(5,40)=562.412, p<0.001$ for level; $\mathrm{F}(4,32)=1.143, p=0.354$ for session; no interaction).

\section{Auditory Selective Attention}

Figure 3 plots detection $\left(d^{\prime}\right)$ as a function of probe frequency. The detectability of a probe drops rapidly as its frequency moves away from the target tone. The results of a three-way ANOVA (frequency $\times$ session $\times$ treatment) showed a significant effect of frequency on signal detectability $(\mathrm{F}(4,32)=8.02, \quad p<0.001)$ and session $(\mathrm{F}(3,33)=4.50, \quad p=0.005) \quad$ but not of treatment
$(\mathrm{F}(1,8)=0.971, \quad p=0.353)$. The results of a two-way repeated-measures ANOVA (frequency $\times$ session) show a statistically significant effect of frequency $(\mathrm{F}(4,32)=4.595$, $p=0.005)$ and session $(\mathrm{F}(4,32)=2.856, p=0.039)$ on signal detectability under placebo. The same kind of analysis performed on data obtained under oxazepam showed a significant effect of frequency $(\mathrm{F}(4,32)=6.171, p<0.001)$ and no overall effect of session $(\mathrm{F}(4,32)=2.028, p=0.077)$, but a significant interaction between signal frequency and session $(\mathrm{F}(16,128)=1.88, p=0.047)$. ANOVAs performed on the estimates of the subjects' internal criterion - that is, the $\beta$ indices derived from the signal-detection-theory analysis - in this selective attention task did not reveal any significant effect.

\section{Streaming}

Firstly, no effect of oxazepam was observed on the falsealarm rate. Figure 4 represents the streaming performance, expressed as $d^{\prime}$, as a function of the frequency separation between the $A$ and $B$ sounds in the ABA sequence. These data were analyzed using a three-way repeated-measures ANOVA (treatment $\times$ session $\times$ frequency separation). The results indicated a statistically significant effect of the frequency separation $(\mathrm{F}(4,32)=31.422, p<0.001)$ on streaming performance but failed to show overall effects of the treatment $(F(1,8)=0.059, p=0.815)$ and session $(\mathrm{F}(4,32)=0.954, p=0.416)$ factors. In order to check whether this lack of overall effect was explained by the inclusion in the analysis of at least two conditions in which

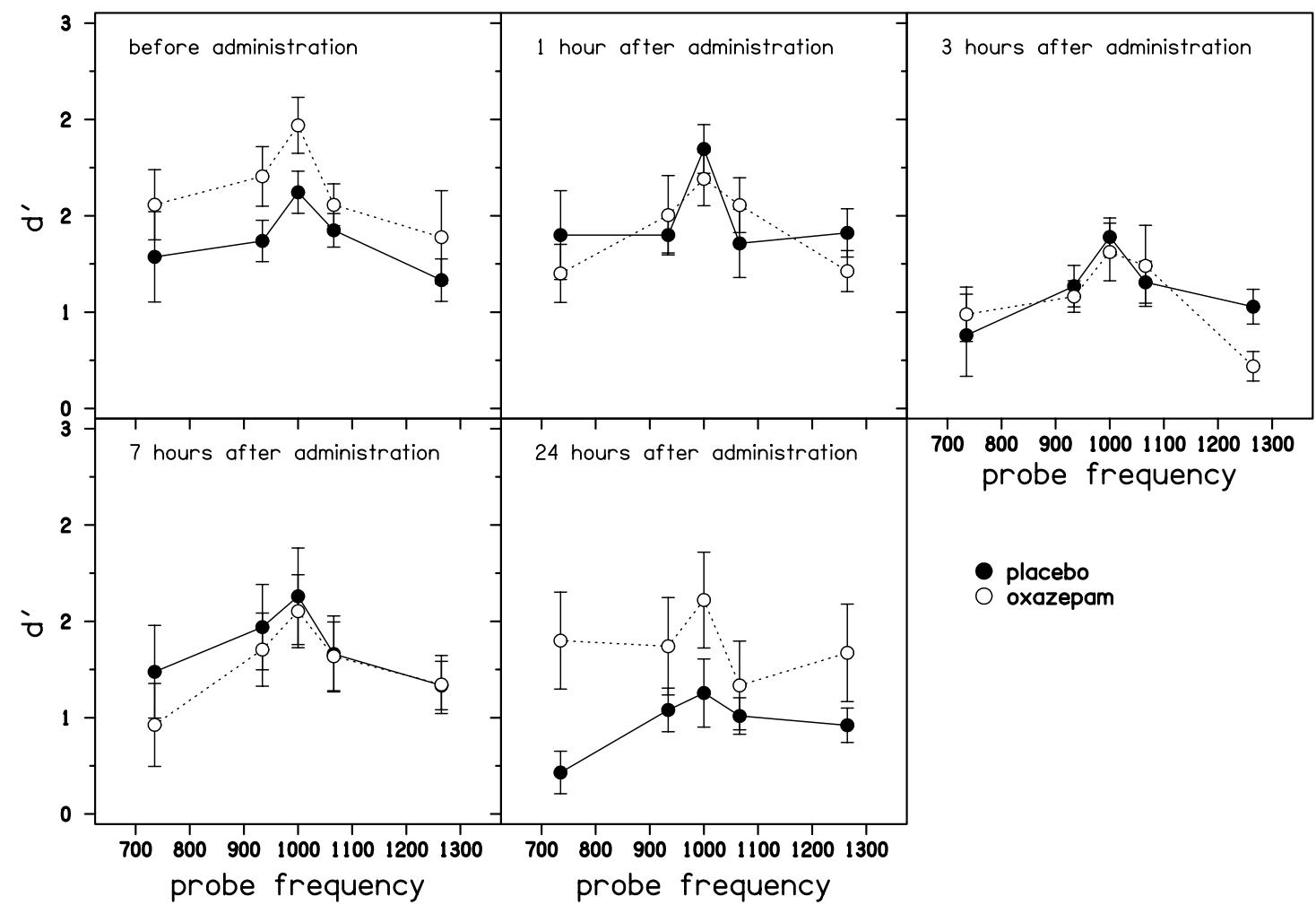

Figure 3 Detection scores $\left(d^{\prime}\right)$ measured under placebo and oxazepam on the different test sessions as a function of frequency of the probe tone in Hz The data points represent the mean detection scores averaged across the nine subjects. The error bars represent the standard errors. The filled circles correspond to data obtained in the placebo condition; the empty circles correspond to data obtained under oxazepam. 


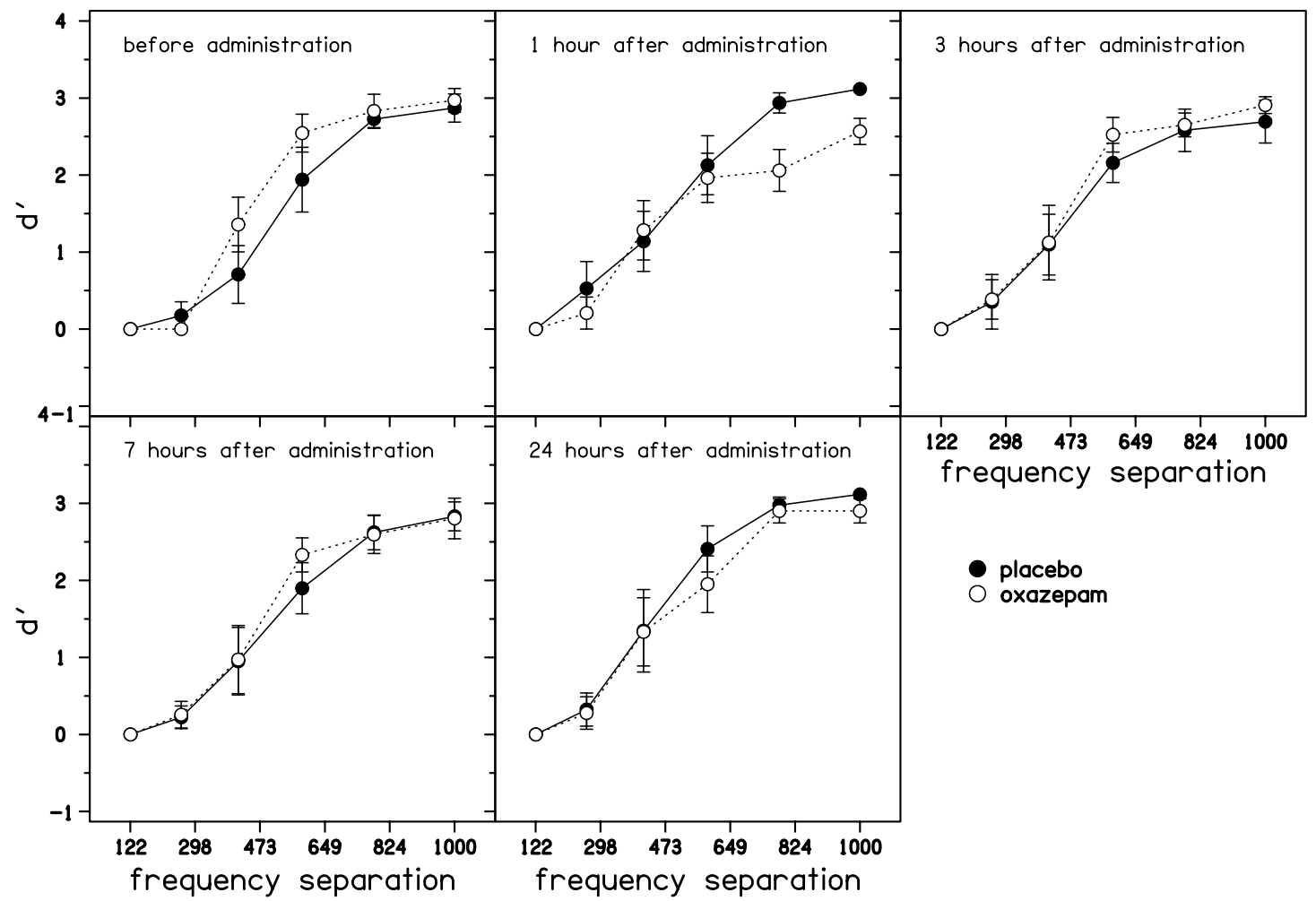

Figure 4 Streaming scores $\left(d^{\prime}\right)$ measured under placebo and oxazepam on the different test sessions as functions of frequency separation. The numbers on the abscissa indicate the frequency separation between the $\mathrm{A}$ and $\mathrm{B}$ tones in $\mathrm{Hz}$. The $\mathrm{d}^{\prime}$ were averaged across subjects. The errors bars represent the standard errors around the means. The filled circles correspond to data obtained in the placebo condition; the empty circles correspond to data obtained under oxazepam.

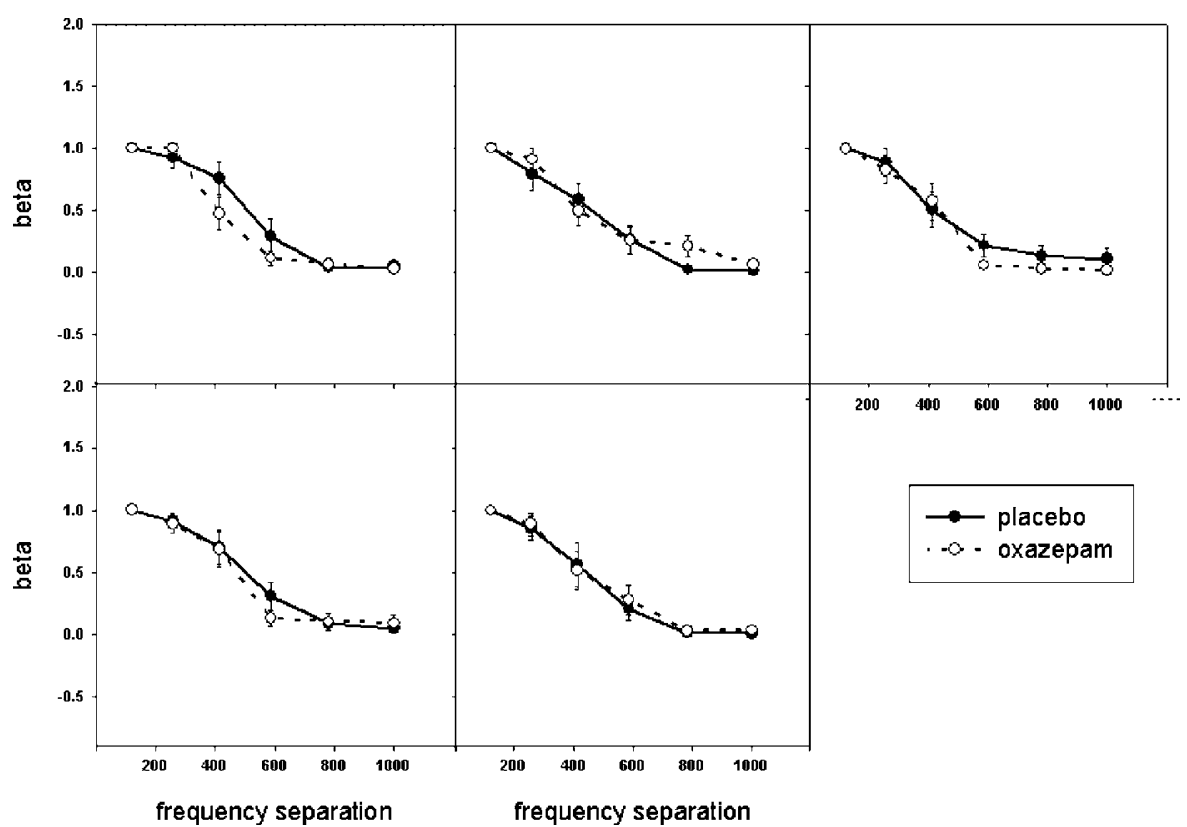

Figure $5 \quad \beta$ indices in streaming measured under placebo and oxazepam on the different test sessions as functions of frequency separation. The numbers on the abscissa indicate the frequency separation between the $\mathrm{A}$ and $\mathrm{B}$ tones in $\mathrm{Hz}$. The $\beta$ were averaged across subjects. The errors bars represent the standard errors around the means. The filled circles correspond to data obtained in the placebo condition; the empty circles correspond to data obtained under oxazepam. 
no difference was expected (namely, the 'before' and ' $24 \mathrm{~h}$ after' control conditions), we performed independent twoway ANOVAs (frequency separation $\times$ treatment) on the data of the sessions in which treatment effect was hypothesized (namely, the ' $1 \mathrm{~h}$ ', ' $3 \mathrm{~h}$ ', and ' $7 \mathrm{~h}$ session'). The results revealed a significant main effect of treatment $1 \mathrm{~h}$ after intake $(\mathrm{F}(1,8)=10.175, p=0.013)$. This effect is apparent on the graphs in the smaller streaming scores obtained under oxazepam at the two largest frequency separations for this test session.

The same statistical analyses as applied on the streaming performance $\left(d^{\prime}\right)$ were performed on the estimates of the subjects' internal criterion - that is, the $\beta$ indices derived from the signal-detection-theory analysis (Figure 5). The results failed to show any significant effect.

\section{DISCUSSION}

The first hypothesis that this study aimed to test was that of an influence of BZDs on auditory sensitivity, as estimated through loudness measures. The results did not show any significant effect of oxazepam intake on categorical loudness judgments, neither between control and test subjects, nor within the latter. Previous reports have shown hyperacousis in subjects during BZD withdrawal (Busto et al, 1988; Lader, 1994; Petursson, 1994). The fact that the present results failed to reveal any hypoacousis following BZD intake, or any hyperacousis several hours after intake-once BZD plasmatic concentration has returned to normal-may be explained by the fact that acute rather than long-term effects of BZDs were addressed in our study. The finding that acute BZD administration does not have an effect on auditory sensitivity throughout the loudness range suggests that the hyperacousis observed at withdrawal proceeds from long-term effects of BZDs on the auditory system. One such long-term effect might consist of a decrease in the affinity of neural receptors to GABA as well as in the permeability of the chloride ion channel, the opening of which is triggered by this neurotransmitter, after prolonged BZD administration (Gallager et al, 1984a,b). Nevertheless, even if loudness functions provide a straightforward means to track changes in loudness perception upon oxazepam, this method is likely to be influenced by central or cognitive mechanisms. Furthermore, loudness functions are perhaps not sensitive enough to detect little variations of loudness perception.

The second hypothesis that was tested in this study regarded the influence of BZD on auditory selective attention. In fact, the results of the present study failed to show any systematic enlargement or shrinking in the selective auditory attention curves under oxazepam. No clear and systematic reduction or enhancement in selective attention is apparent in the graphs throughout the different test sessions. This lack of clear effect of BZDs on auditory selective attention, in spite of the fact that BZDs influence neural inhibitory mechanisms that are likely to play a role in the ability to focus attention on a narrow range of frequencies, can be explained in several ways. A first interpretation is that the expected influence of BZDs on selective auditory attention was obscured by the large across- as well as within-subject variability observed in this study. The selective auditory attention curves were indeed different between the placebo and oxazepam groups even before the substances were administrated. Furthermore, within a given group, the detection performance fluctuates over time. The alternative interpretation is that oxazepam really had no influence on selective auditory attention, which implies that selective auditory attention is not subtended by the kind of neural inhibition mechanisms upon which BZDs have an influence.

The third hypothesis addressed in this study concerned the influence of BZDs on auditory streaming. The results revealed a significant difference in auditory streaming performances between test and control subjects $1 \mathrm{~h}$ after the intake of oxazepam or placebo. Since oxazepam had no significant influence on loudness, it is unlikely that the diminution in streaming performance observed in this experiment was related to a diminution in the loudness of stimuli. This diminished streaming performance cannot be explained by a shift in the subjects' internal decision criterion since, as indicated by the results of the signaldetection-theory analysis, the $\beta$ indices did not significantly vary as a function of delay after oxazepam intake and were not significantly different between the two groups. Consequently, the decrease in the number of 'two-stream' responses that was observed at the largest frequency separations probably reflects a real degradation in auditory stream segregation abilities. As mentioned in the Introduction, one of the reasons for which an influence of BZDs on auditory streaming was expected was via selective auditory attention. However, since the results failed to show an effect of BZD on selective auditory attention probably stemming from the insufficient data points, it is impossible to give a conclusion. The most likely interpretation of the observed decrease in perceptual stream segregation $1 \mathrm{~h}$ after oxazepam intake is that BZD influences the interplay between inhibitory and excitatory mechanisms upon which stream segregation is based. As a result of their known potentiating action on inhibitory neuromediator GABA, BZD may disturb the balance between excitatory and inhibitory processes. This disturbing influence would result in a reduced ability of the subject to organize sequential sounds into perceptual streams.

Another interpretation relates to the recently demonstrated inhibitory influence of BZDs on perceptual binding (Giersch et al, 1995) and early stimulus-locked $40-\mathrm{Hz}$ responses in the mid-latency-evoked potentials are reduced by BZDs (Jääskeläinen et al, 1999). Such $40-\mathrm{Hz}$ components in the EEG might constitute a correlate of the perception and perceptual fusion of successive acoustic events (Pulvermüller et al, 1997). Streaming, defined as the splitting of acoustic events into distinct auditory objects, can be conceived as the converse of auditory grouping or binding. Thus, the observation in the present study of a reduction in auditory streaming under oxazepam can be thought of as another manifestation of the inhibitory influence of BZDs upon the neural mechanisms underlying the perceptual binding of different aspects or parts of sensory stimuli. This interpretation, however, is speculative and further data on the effect of BZD on binding processes in other sensory modalities become available in the literature. 


\section{CONCLUSION}

The influence of acute oxazepam intake on various aspects of auditory perception was tested. The results revealed no effect on loudness, neither immediately following nor several hours after oxazepam intake. It is suggested that the observation of hyperacousis during BZD withdrawal reported in earlier studies proceeds from long-term rather than short-term effects of BZDs over the auditory system. Secondly, although a significant difference was found between the control and oxazepam groups $3 \mathrm{~h}$ after oxazepam or placebo intake, no clear, systematic effect on selective auditory attention was observed. Thus, although BZDs have been shown to have a detrimental effect on vigilance and visual attention, they do not appear to exert a significant influence on selective attention in the auditory modality, at least in the short term. Owing to large interand intra-subject variability of the results, whether this absence of significant effect reflects a genuine lack of influence of oxazepam on auditory selective attention, or insufficient sensitivity of the test remains undetermined, no firm conclusion as to the relation between streaming and auditory selective attention can thus be reached. Finally, a significant reduction of auditory streaming performances was observed $1 \mathrm{~h}$ after oxazepam intake. As indicated by an analysis of the results in terms of the signal-detection theory, this reduction is not caused by a modification in the attitude of the subjects toward the task; it reflects a real decrease in the perceptual sound segregation performance. This result is consistent with a role of inhibitory, GABAmediated mechanisms in the auditory perceptual organization of sound sequences. This is consistent with current, physiologically based computer models for streaming, which all involve inhibitory mechanisms as a crucial aspect of their functioning.

In more general terms concerning auditory perception, the deteriorated stream segregation under oxazepam could affect how sensory information is organized into perceptual entities or 'objects'. In everyday life the sound reaching our ears arises from a number of different sources. For one to be able to hear out and follow a voice among background noises, or the sound of a violin among other instruments in an orchestra, frequency components emanating from the same acoustic source must be grouped together-and separated from components arising from other sourcesacross both frequency and time. We demonstrated in this study that BZDs affect the grouping of sound events across time and their integration into a coherent perceptual stream, and so could affect how sensory information is organized in coherent perceptual entities. It would be interesting to evaluate the effect of long-term administration of BZD on these processes, considering the importance of auditory perception in everyday life.

\section{ACKNOWLEDGEMENTS}

The authors thank Jacqueline Julien and Marion Genoulaz for their contribution in the recruitment of subjects. We also thank Valérie Vidon, Fabienne Antetomaso, and all the other nurses in UCPB in Bron for their help. This work was supported in part by a grant from the Ministry of Research and Technology to the first author.

\section{REFERENCES}

Adams JC, Mugnaini E (1984). Dorsal nucleus of the lateral lemniscus: a nucleus of GABAergic projection neurons. Brian Res Bull 13: 585-590.

Allen JB, Hall JL, Jent PS (1990). Loudness growth in 1/2 octave bands (LGOB) - a procedure for the assessment of loudness. JASA 88: 745-753.

Beauvois MW, Meddis R (1991). A computer model of auditory stream segregation. Q J Exp Psychol A 43: 517-541.

Beauvois MW, Meddis R (1996). Computer simulation of auditory stream segregation in alternating-tone sequences. J Acoust Soc Am 99: 2270-2280.

Bregman AS (1990). Auditory Scene Analysis. MIT Press: Cambridge, MA.

Bregman AS, Campbell J (1971). Primary auditory stream segregation and perception of order in rapid sequences in tones. J Exp Psychol 89: 244-249.

Brown MW, Brown J, Bowes JB (1989). Absence of priming coupled with substantially preserved recognition in lorazepaminduced amnesia. Q J Exp Psychol 41A: 599-617.

Brown J, Lewis V, Brown M, Horgn G, Bowes JB (1982). A comparison between transient amnesias induced by two drugs (diazepam and lorazepam) and amnesia of organic origin. Neuropsychologia 20: 55-70.

Busto U, Fornazzi L, Naranjo CAA (1988). Protacted tinnitus after discontinuation of long-term therapeutic use of benzodiazepines. J Clin Psychopharmacol 8/5: 359-362.

Carlyon RP, Cusack R, Foston JH, Robertson IH (2001). Effects of attention and unilateral neglect on auditory stream segregation. $J$ Exp Psychol Hum Percept Perform 27: 115-127.

Carter CS, Maddock R, Chaderjian M, Post R (1998). Attentional effects of single dose triazolam. Prog Neuropsychopharmacol Biol Psychiatry 22: 279-292.

Choi DW, Farb DH, Fischbach GD (1977). Chlordiazepine selectivity potentiates GABA conductance of spinal cord cell cultures. Nature 269: 342-344.

Clark JM (1996). Contributions of inhibitory mechanisms to unified theory in neuroscience and psychology. Brain Cognition 30: 127-152.

Clarke PRF, Eccerley PS, Frisby JP, Thornson JA (1970). The amnesic effect of diazepam (Valium). Br J Anaesth 42: 690-697.

Dai H, Scharf B, Buus S (1991). Effective attenuation of signals in noise under focused attention. JASA 89: 2837-2842.

Danion HM, Peretti S, Grange D, Bilik M, Imbs JL, Singer L (1992). Effects of chlorpromazine and lorazepam on explicit memory, repetition priming and cognitive skill learning in healthy volunteers. Psychopharmacology 108: 345-351.

Desimone R, Duncan J (1995). Neural mechanisms of selective visual attention. Annu Rev Neurosci 18: 193-222.

Dupont JM, Geffard A, Cals A, Aran JM (1990). Immunohistochemical evidence for GABAergic cell bodies in the medial nucleus of the trapezoid body and lateral vestibular nucleus in the guinea pig brainstem. Neurosci Lett 111: 263-268.

Fubara BM, Casseday JH, Covey E, Schwartz-Bloom RD (1996). Distribution of GABAa, GABAb, and glycine receptors in the central auditory system of the big brown bat, Eptisiscus fuscus. $J$ Comp Neurol 369: 83-92.

Gallager DW, Lakoski JM, Gonsalves SF, Rauch SL (1984a). Chronic benzodiazepine treatment decreases postsynaptic GABA sensitivity. Nature 308: 74-77.

Gallager DW, Rauch SL, Malcolm AB (1984b). Alterations in a low affinity GABA recognition site following chronic benzodiazepine treatment. Eur J Pharmacol 98: 159-160.

Ghatan PH, Hsieh JC, Petersson KH, Stone-Elander S, Ingvar M (1998). Coexistence of attention-based facilitation and inhibition in the human cortex. Neuroimage 7: 23-29. 
Giard MH, Fort A, Mouchetant-Rostaing Y, Pernier J (2000). Neurophysiological mechanisms of auditory selective attention in humans. Front Biosci 5: 84-94.

Giersch A, Boucart M, Danion JM, Vidailhet P, Legrand F (1995). Effects of lorazepam on perceptual integration of visual forms in healthy volunteers. Psychopharmacology 119: 105-114.

Greenberg G, Larkin W (1968). Frequency-response characteristic of auditory observers detecting signals of a single frequency in noise: the probe signal method. JASA 44: 1513-1523.

Helfert RH, Bonneau JM, Wenthold RJ, Altschuler RA (1989). GABA and glycine immunoreactivity in the guinea pig superior olivary complex. Brain Res 501: 269-286.

Jääskeläinen IP, Hirvonen J, Saher M, Pekkonen E, Sillanaukee P, Näätänen $\mathrm{R}$ et al (1999). Benzodiazepine temazepam suppresses the transient auditory $40-\mathrm{Hz}$ response amplitude in humans. Neurosci Lett 268: 105-107.

Johnson DN, Weingartner HJ, Andreason P, George DT (1995). An effect of triazolam on visual attention and information processing. Psychopharmacology 121: 145-149.

Joliot M, Ribary U, Llinas RR (1994). Human oscillatory brain activity near $40 \mathrm{~Hz}$ coexist with cognitive temporal binding. Proc Natl Acad Sci 91: 11748-11751.

Jones MR (1976). Time, our lost dimension: toward a new theory of perception, attention, and memory. Psychol Rev 83: 323-355.

Jones MR, Maser DJ, Kidd GR (1978). Rate and structure in memory for auditory patterns. Mem Cognit 6: 246-258.

Kawashima R, Imaizumi S, Mori K, Okada K, Goto R, Kisitani S, Ogawa A, Fukada H (1999). Selective visual and auditory attention toward utterances-a PET study. Neuroimage 10: 209215.

Knopman D (1991). Unaware learning versus preserved learning in pharmacological amnesia: similarities and differences. $J$ Exp Psychol (Learn Mem Cognit) 17: 1017-1029.

Knowles JA, Ruelieus JH (1972). Absorption and excretion of 7 chloro-1,3 dihydro-3-hydroxy-5-phenyl-2H-1,4 benzodiazepine2-one (oxazepam) in humans. Detrmination of the drug by gasliquid chromatography with electron capture detection. Arzneimittelforschung 22: 687-692.

Lader M (1994). Benzodiazepine dependence. Prog Neurol Psychopharmacol Biopsychiatr 8/1: 85-95.

Macdonald RL, Barker JL (1978). Different actions of anticonvulsant and anesthetic barbiturates revealed by use of cultured mammalian neurons. Science 200: 775-777.

MacMillan NA, Creelman CD (1991). Detection Theory: A User's Guide. Cambridge University Press: Cambridge.

Mc Cabe SL, Denham MJ (1996). A model of auditory streaming. J Acoust Soc Am 101: 1611-1621.

Moore JK, Moore RY (1987). Glutamic acid decarboxylase-like immunoreactivity in brainstem auditory nuclei of the rat. J Comp Neurol 260: 157-174.

Moran J, Desimone R (1985). Selective attention gates visual processing in the extrastriate cortex. Science 229: 782-784.

Morand N, Veuillet E, Gagnieu MC, Lemoine P, Collet L (1998). Benzodiazepines alter cochleo-cochlear loop in humans. Hearing Res 121: 71-76.

Muganini E, Oertel WH (1985). An atlas of the distribution of GABAergic neurons and terminals in the rat CNS as revealed by GABA immunohistochemistry. In: Björklund A, Hökfelt T (eds). Handbook of Chemical Neuroanatomy, Vol. 4: GABA and Neuropeptides in the CNS, Part I. Elsevier Science Publishers: Amsterdam. pp 436-553.
Petursson H (1994). The benzodiazepine withdrawal syndrome. Addiction 89: 1455-1459.

Peyret D, Geffard M, Aran JM (1986). GABA immunoreactivity in the primary nuclei of the auditory central nervous system. Hearing Res 23: 115-121.

Pulvermüller F, Birbaumer N, Lutzenberg W, Mohr B (1997). Highfrequency brain activity: its possible role in attention, perception and language processing. Prog Neurobiol 52: 427-445.

Scharf B (1989). Spectral specificity in auditory detection: the effect of listening on hearing. JASA 10: 309-317.

Scharf B, Magnan J, Collet L, Ulmer E, Chays A (1994). On the role of the olivocochlear bundle in hearing: a case study. Hearing Res 75: 11-26.

Scharf B, Magnan J, Collet L, Ulmer E, Chays A (1997). On the role of the olivocochlear bundle in hearing: 16 case studies. Hearing Res 103: 101-122.

Scharf B, Quigley S, Aoki C, Peachey N, Reeves A (1987). Focused auditory attention and frequency selectivity. Percept Psychophys 42: 215-223.

Sellal F, Danion JM, Kauffman-Muller F, Grange D, Imbs JL, Van der Linden $M$ et al (1992). Differentials effects of diazepam and lorazepam on repetition priming in healthy volunteers. Psychopharmacology 108: 371-379.

Sivilotti L, Nistri A (1991). GABA receptor mechanisms in the central nervous system. Prog Neurobiol 36: 35-92.

Snodgrass JG, Corwin M (1988). Pragmatics of measuring recognition memory. Application to dementia and amnesia. $J$ Exp Psychol Gen 117: 34-50.

Thompson GC, Cortez AM, Lam DMK (1985). Localization of GABA immunoreactivity in the auditory brainstem of guinea pigs. Brain Res 339: 119-122.

Tiitinen H, Sinkkonen J, Reinikainen K, Alho K, Lavikainen J, Naatanen R (1993). Selective attention enhances the auditory 40 $\mathrm{Hz}$ transient response in humans. Nature 364: 59-60.

van Noorden LPAS (1975). Temporal coherence in the perception of tone sequences, $\mathrm{PhD}$ dissertation. IPO, The Netherlands.

Vater M, Kössl M, Horn AKE (1992). GAD and GABAimmunoreactivity in the ascending auditory pathway of horseshoe and mustached bats. J Comp Neurol 325: 183-206.

Walley RE, Weiden TD (1973). Lateral inhibition and cognitive masking: a neuropsychological theory of attention. Psychol Rev 80: 284-302.

Wenthold RJ, Zempel MH, Parakkal KA, Reeks KA, Altschuler RA (1986). Immunocytochemical localization of GABA in the cochlear nucleus of the guinea pig. Brain Res 380: 7-18.

Winer JA (1986). Neurons accumulating [3H] gamma-aminobutyric acid (GABAZ) in supragranular layers of cat primary auditory cortex. Neuroscience 19: 771-793.

Woldorff MG, Gallen CC, Hampson SA, Hillyard SA, Pantev C, Sobel D et al (1993). Modulation of early sensory processing in human auditory cortex during auditory selective attention. Proc Natl Acad Sci 90: 8722-8726.

Woldorff MG, Hillyard SA, Gallen CC, Hampson SR, Bloom FE (1998). Magnetoencephalographic recordings demonstrate attentional modulation of mismatch-related neural activity in human auditory cortex. Psychophysiology 35: 283-292.

Woods JH, Katz JL, Winger G (1987). Abuse liability of benzodiazepines. Pharmacol Rev 39: 251-398.

Wynne B, Harvey AR, Robertson D, Sirinathsinghji DJS (1995). Neurotransmitter and neurmodulators systems of the rat inferior colliculus and auditory brainstem studied by in situ hybridization. J Chem Neuroanat 9: 289-300. 